\title{
Entre o desejo e o medo: as representações sociais das adolescentes acerca da iniciação sexual*
}

\author{
BETWEEN DESIRE AND FEAR: FEMALE ADOLESCENTS' SOCIAL \\ REPRESENTATION ON SEXUAL INITIATION
}

\section{ENTRE EL DESEO Y EL MIEDO: LAS REPRESENTACIONES SOCIALES DE LAS ADOLESCENTES SOBRE LA INICIACIÓN SEXUAL}

\section{Marta Araújo Amaral', Rosa Maria Godoy Serpa da Fonseca²}

\section{RESUMO}

Este artigo apresenta um dos temas emergentes de uma pesquisa qualitativa, desenvolvida com adolescentes do sexo feminino da Vila Acaba Mundo Belo Horizonte/MG. Teve como objetivo compreender as representações sociais das adolescentes em relação à iniciação sexual sob o recorte de gênero. Os dados foram colhidos em quatro Oficinas de Trabalho e analisados à luz da teoria das representações sociais, sendo utilizada a técnica da análise de discurso. Duas categorias empíricas emergiram dos discursos: deixar de ser criança e temor pela gravidez e suas consequiências. $\mathrm{O}$ entendimento das representações sociais e das relações de gênero evidenciou valores, idéias e práticas das adolescentes e suas famílias em freqüentes transformações, dentro do campo social.

\section{DESCRITORES}

Adolescente.

Sexualidade.

Identidade de gênero.

\section{ABSTRACT}

This article discusses one of the emergent themes of a qualitative research carried out with female adolescents in the neighborhood of Acaba Mundo, in the city of Belo Horizonte, State of Minas Gerais, and aims at understanding their social representations on sexual initiation concerning gender. The data was collected in four workshops and analyzed on the basis of the social representation theory by means of the discourse analysis technique. Two empirical categories and their consequences emerged from the discourse: leaving childhood behind and fear of pregnancy. The understanding of the social representations and of the gender relationships made the values, ideas and practices of the adolescents and their family clear. It also made clear that those values, ideas and practices were in frequent transformation in the social field.

\section{KEY WORDS}

Adolescent.

Sexuality.

Gender identity.

\section{RESUMEN}

En este estudio se presentan dos temas emergentes de una investigación cualitativa, desarrollada con adolescentes del sexo femenino de la Vila Acaba Mundo Belo Horizonte/MG. Tuvo como objetivo comprender las representaciones sociales de las adolescentes en relación a la iniciación sexual bajo el recorte de género. Los datos fueron recolectados en cuatro Talleres de Trabajo y analizados a la luz de la teoría de las representaciones sociales, sendo utilizada la técnica del análisis de discurso. Dos categorías empíricas emergieron de los discursos: dejar de ser niño y temor por el embarazo y sus consecuencias. El entendimiento de las representaciones sociales y de las relaciones de género evidenció valores, ideas y prácticas de las adolescentes y sus familias en frecuentes transformaciones, dentro del campo social.

\section{DESCRIPTORES}

Adolescente.

Sexualidad.

Identidad de género.

\footnotetext{
* Extraído da tese "Entre o desejo e o medo: Oficinas de Trabalho como espaço de reflexão e empoderamento de adolescentes", Escola de Enfermagem da Universidade de São Paulo (EEUSP), 2005.

1 Doutora em Enfermagem Professora Adjunta da Escola de Enfermagem da Universidade Federal de Minas Gerais. martamaral@ grude.ufmg.br 2 Doutora em Enfermagem, Professora LivreDocente da EEUSP. rmgsfon@usp.br
} 


\section{INTRODUÇ̃̃O}

A sexualidade na adolescência foi abordada durante muito tempo sob o aspecto biológico e reprodutivo. Hoje, porém, não podemos ignorar a importância do componente afetivo, considerando sua influência na formação da identidade e no comportamento do jovem nas mais diferentes situações que enfrenta no seu cotidiano.

A iniciação sexual na adolescência é abordada por autores de diferentes nacionalidades, o que reforça a idéia de ser este um tema comum à realidade de diferentes países, independente de seu grau de desenvolvimento ${ }^{(1-6)}$.

O exercício da sexualidade traz implicações no processo reprodutivo e na saúde bio-psico-social do adolescente. A decisão de iniciar as relações sexuais acontece paralelamente a inúmeras modificações na vida do adolescente, podendo gerar situações indesejadas como a ocorrência de gravidez, aborto, doenças sexualmente transmissíveis e outras. Tais situações repercutem não apenas na fase da adolescência como também na vida futura.

Em relação ao comportamento sexual, estudos apresentam a antecipação das idades feminina e masculina para a iniciação sexual nas últimas décadas, o crescimento da taxa de fecundidade no grupo juvenil, a utilização mais precoce de métodos anticoncepcionais e a associação entre o início da vida sexual e o menor nível de escolarização dos adolescentes ${ }^{(7-8)}$.

Em Oficinas de Trabalho realizadas com adolescentes pudemos perceber o ritmo de cada grupo, o interesse crescente em discutir questões ligadas à sexualidade e a predominância de uma inquietação: a iniciação sexual. Essa questão surgia muitas vezes de forma velada, outras vezes durante a discussão de outros temas, porém sempre gerava muito interesse no grupo. Nas discussões surgiam sentimentos distintos como medo, prazer, desejo por conhecer algo novo, sendo as opiniões divergentes daquelas assumidas por seus pais e por suas amigas/ amigos, segundo elas mesmas.

Atentos a essa inquietação, percebemos que ela retornava com freqüência às discussões, fazendo parte do presente e do futuro dessas adolescentes. Observamos também que a iniciação sexual encontrava-se imbricada a dois outros aspectos: formação da identidade feminina e planos de vida. Essa ligação, porém, não se mostrava de forma clara, merecendo um aprofundamento sobre o significado atribuído pelas adolescentes a essas questões.

Revendo a literatura e traçando um paralelo com a experiência vivenciada com o grupo de adolescentes, pude- mos perceber uma rede de interações, mas também de vazios que necessitam ser preenchidos, além de indagações que merecem respostas para o aprimoramento e redimensionamento de futuros trabalhos.

Com base no exposto, propomos este estudo numa vertente compreensiva, no qual buscamos compreender as Representações Sociais das adolescentes em relação à iniciação sexual sob o enfoque de gênero. Visamos, com este estudo, apresentar subsídios para futuros trabalhos com adolescentes, partindo do real significado que eles atribuem à iniciação sexual.

\section{MÉTODO}

Para desenvolver esta pesquisa optamos pela abordagem qualitativa por possibilitar uma aproximação do universo de significações, motivos, aspirações, atitudes, crenças e valores das adolescentes em estudo.

Os métodos qualitativos enfatizam as particularidades de um fenômeno em termos de seu significado para o grupo pesquisado. Permite um mergulho em profundidade dentro de um grupo, desvelando questões importantes para o tema pesquisado $^{(9-10)}$.

O referencial teórico selecionado para este estudo foi a Teoria das Representações Sociais na perspectiva da Psicologia Social, aqui entendida como o conhecimento socialmente construído que tem como função a elaboração de comportamentos e a comunicação entre indivíduos ${ }^{(11)}$.

Ao utilizar essa teoria, buscamos compreender de forma ampliada a realidade cotidiana da adolescente, sem isolá-la de sua vida e sua história. Pretendemos, assim, nos aproximar do pensamento individual, porém articulando-o com o social, fazendo uma ligação entre o interno (o pensamento da adolescente) e o externo (que concretiza os fenômenos sociais)

Para o alcance dessa proposta, serão analisados dois processos referentes à elaboração e ao funcionamento de uma representação - objetivação e ancoragem - processos que apresentam a articulação entre a atividade cognitiva e as condições sociais em que são forjadas as representações ${ }^{(12-13)}$.

Acreditamos que a compreensão das representações sociais das adolescentes em relação a iniciação sexual será enriquecida e ampliada com um olhar generificado, evidenciando o modo como se organizam as relações de gênero e suas interferências na formação da identidade feminina, na vivência sexual e nos planos de vida. 


\section{Cenário do estudo}

Este estudo foi realizado na Associação Querubins, uma organização não-governamental, que atende 180 crianças e adolescentes com idade entre 6 e 18 anos, na grande maioria, moradores da Vila Acaba Mundo, localizada na região sul de Belo Horizonte. A sede da Associação Querubins está situada próxima à Vila Acaba Mundo, em um espaço cedido em comodato pela Mineradora Lagoa Seca e foi construída, gradativamente, com muito esforço dos coordenadores e da comunidade, contando hoje com 10 salas, duas tendas cobertas com lonas, quadra de esportes, horta orgânica, viveiro de mudas medicinais, biblioteca, etc. Atualmente o Projeto Querubins oferece oficinas de dança, percussão, artes plásticas, construção de instrumentos musicais, capoeira, manutenção de horta orgânica, computação, esportes, apoio escolar e psicológico, dentre outros. O Projeto conta com vinte instrutores (contratados/voluntários), dentre eles dançarinos, músicos, psicólogos, enfermeiras, pedagogas, agrônomo, artistas plásticos e ex-educandos, que se tornaram instrutores/monitores. Os adolescentes e as crianças participam diariamente de três oficinas distintas.

\section{Sujeitos do estudo}

Adolescentes do sexo feminino, com idade entre 11 e 16 anos, em número de dezesseis (16), subdivididas em 3 grupos. Tal divisão foi proposta pelas próprias adolescentes que alegaram outras atividades na instituição nos horários propostos para realização das oficinas, porém no decorrer das mesmas foi possível perceber que esta divisão foi feita considerando faixa etária, afinidades entre as participantes e o tipo de interesse do grupo por determinados assuntos.

O grupo 1 foi formado por cinco adolescentes com idade entre 14 e 16 anos. Todas viviam na Vila desde que nasceram. Duas delas viviam com a mãe e irmãos; duas com pai, mãe e irmãos; uma com o pai e madrasta (devido ao falecimento da mãe). A escolaridade do grupo variava entre a $7^{\mathrm{a}}$ série do $1^{\circ}$ grau e a $1^{\mathrm{a}}$ série do $2^{\circ}$ grau.

O grupo 2 foi formado por oito (8) adolescentes com idade entre 12 e 14 anos. Quatro delas nasceram na Vila e 4 ali viviam desde os quatro anos de idade. Nesse grupo, quatro adolescentes viviam com pai/mãe/irmãos, sendo freqüente a presença de outro familiar, como tio e primos; duas adolescentes moravam com as avós e uma com a mãe e o padrasto. A escolaridade desse grupo variava entre a $4^{\mathrm{a}}$ e $7^{\mathrm{a}}$ série, com predomínio da $6^{\mathrm{a}}$ série.

O grupo 3 foi formado por três (3) adolescentes com idade entre 11 e 13 anos. Duas viviam na Vila desde que nasceram e uma delas vivia na Vila há um ano, aproximadamente. Uma morava com a tia e primos; uma com a mãe e o padrasto; uma com o pai e a madrasta (devido ao falecimento da mãe). As três adolescentes, na ocasião, estavam cursando a $4^{\mathrm{a}}$ série do $1^{\mathrm{o}}$ grau. Nos três grupos destacou-se uma característica comum em relação à profissão dos pais: as mães, madrastas e avós eram faxineiras, empregadas domésticas e do lar. Os pais e padrastos eram pedreiros.

\section{Inserção da pesquisadora no campo de estudo}

Com o objetivo de conhecer o contexto em que as adolescentes estavam inseridas, de conhecer as necessidades do grupo e de criar um espaço de debate e reflexão com as adolescentes sobre questões referentes à sexualidade e saúde, iniciamos em maio de 2002 os primeiros contatos com a coordenação do projeto Querubins e participamos de diferentes Oficinas. Durante a reunião promovida trimestralmente pela Associação Querubins, a proposta da Oficina de Sexualidade foi apresentada aos pais, que revelaram boa receptividade em relação ao trabalho a ser desenvolvido.

Essa fase de trabalho de campo, denominada como período exploratório, apresenta como seu

\section{principal objetivo proporcionar, através da imersão do pes- quisador no contexto, uma visão geral do problema conside- rado, contribuindo para a focalização das questões e da identificação de informantes e outras fontes de dados ${ }^{(14)}$.}

Os encontros com as adolescentes tiveram início em agosto de 2002 e, por solicitação das próprias adolescentes, os grupos foram subdivididos desde o primeiro encontro. Todos os encontros foram documentados, acrescentados de comentários posteriores a cada sessão. Esses registros constituíram um diário de campo.

\section{Coleta de dados}

Para este estudo, especificamente, foram realizadas quatro (4) Oficinas de Trabalho com três grupos diferenciados por faixa etária, perfazendo um total de doze (12) Oficinas, as quais foram realizadas nos meses de novembro e dezembro de 2003, tendo cada Oficina a duração aproximada de uma hora e meia. As Oficinas foram assim intituladas:

1- Iniciação sexual: o que penso sobre isso?

2- Ser adolescente e ser mulher

3- Uma vida pela frente: onde quero chegar?

4 Oficina de Trabalho: como cheguei...como estou?

Para cada grupo foram informados os objetivos e critérios adotados nessa pesquisa e solicitada a autorização para o registro das falas.

\section{Aspectos éticos}

Atendendo à Resolução 196, de outubro de 1996, do Conselho Nacional de Saúde, foi solicitada à Coordenadora do Projeto Querubins, aos responsáveis legais pelas adolescentes e a cada integrante das Oficinas a assinatura de um Termo de Livre Consentimento para participação das 16 
adolescentes na pesquisa. O projeto foi analisado pelo Comitê de Ética em Pesquisa da Escola de Enfermagem da USP, com aprovação em 21 de novembro de 2003.

\section{Análise dos dados}

As Oficinas foram gravadas e transcritas na íntegra. A análise dos dados coletados foi feita através da técnica da análise de discurso, que tem como objetivo básico

realizar uma reflexão geral sobre as condições de produção e apreensão da significação de textos produzidos nos mais diferentes campos: religioso, filosófico, jurídico e sociopolítico. Ela visa compreender o modo de funcionamento, os princípios de organização e as formas de produção social do sentido(10).

Buscamos entender os discursos de forma situada e contextualizada, atentos aos inúmeros fatores que influenciam a vivência da sexualidade pelas adolescentes.

\section{DISCUSSÃO}

Ao analisar os discursos, percebe-se que falar sobre sexualidade não é uma tarefa fácil para os pais e filhas adolescentes, independente da faixa etária em que se encontram, porém as conotações apresentadas por cada grupo são distintas.

Para as adolescentes mais jovens, a ausência de diálogo com os pais traz um certo alívio e conforto, mostrando-se como uma forma de defesa para sua inibição de falar sobre o assunto. Discutir sobre a iniciação sexual com os pais pode representar, ainda, que elas estejam desejando ter ou já tenham uma vida sexual ativa, o que constitui uma barreira para comunicação entre eles. Essa ausência de diálogo faz com que algumas adolescentes desconheçam o comportamento dos pais diante de uma situação concreta de iniciação sexual. Para justificar a falta de diálogo sobre sexualidade, uma adolescente diz: minha mãe nem sabe o que é isto (G2.5).

As adolescentes com mais idade evitam falar com a mãe sobre sua vida afetiva, temendo que as informações cheguem até o pai, parentes e vizinhos, tornando de domínio público questões que são particulares. Na visão dessas adolescentes, os pais não estão preparados e não sentem segurança para discutir com os filhos questões sobre sexualidade. Algumas destacaram a importância dos pais adquirirem mais conhecimento para que esta realidade de distanciamento e silêncio seja modificada.

As exceções merecem ser mencionadas: três adolescentes relataram uma maior abertura em conversar com as mães sobre sexualidade e outros assuntos ligados à vida afetiva. O comportamento destas adolescentes em outros momentos das Oficinas caracterizou-se pela facilidade em expressar suas opiniões, maior naturalidade para discutir os temas propostos, mais firmeza nos posicionamentos. Essa constatação leva a um necessário repensar sobre como um relacionamento de família, pautado no diálogo, contribui para a vida cotidiana de pais e filhos.

Um estudo realizado com adolescentes de escolas particulares e públicas de São Paulo, também constatou um comportamento diferenciado de jovens que relatavam um diálogo aberto com os pais, inclusive para discutir assuntos relacionados à sexualidade. Tais adolescentes revelaram-se mais seguros no estabelecimento de suas relações afetivas. A autora reforça a importância da família não se alienar da realidade vivida pelos adolescentes e de suas descobertas na área da sexualidade, na medida em que a atividade sexual vem fazendo parte do namoro e cabendo ao adolescente decidir quando e como iniciá-la ${ }^{(8)}$.

Em relação ao diálogo entre pais e filhos, um outro aspecto interfere na relação familiar. Para que o diálogo ocorra são necessárias a vontade e a abertura para encontrar o outro, contudo, o que ocorre na comunicação de muitos pais e filhos é uma sucessão de acusações, em que o filho lamenta e os pais criticam e repreendem ${ }^{(15)}$.

Tal situação ficou evidenciada em vários momentos das Oficinas, quando se discutiu sobre relacionamento familiar. Muitas adolescentes se queixaram do comportamento cotidiano de seus pais, marcado por muitas cobranças e punições, e expressaram sentimentos de tristeza e de decepção por não serem reconhecidos seus esforços. Destacaram, ainda, o comportamento diferenciado dos pais em relação aos filhos do sexo masculino, concedendo-lhes regalias e permitindo-lhes vivenciar com mais liberdade sua sexualidade.

É importante ressaltar que, quando as adolescentes se referem ao comportamento dos pais, destacam a figura materna como esteio da família no sentido econômico e afetivo, assumindo a responsabilidade da manutenção da casa e criação dos filhos. Assim, a mãe se mostra mais próxima, mais compreensiva, com presença mais significativa na vida das filhas. A imagem da mãe provedora, responsável, ativa e decidida foi transmitida pela maioria das adolescentes.

A figura paterna foi pouco mencionada e, quando referenciada, mostrou um pai repressor, inflexível em suas decisões e distante dos filhos, mas que se julga no direito de punir, muitas vezes de forma violenta, tendo como atitudes trancar a filha em casa, bater, colocá-la para fora de casa se ficar grávida. Esse tipo de comportamento reforça os poucos vínculos com a figura paterna e naturaliza a ausência de diálogo entre pai e filhos.

As adolescentes reconheceram que existe uma constante preocupação de pais e mães com a gravidez precoce das filhas. Inúmeros foram os relatos de reações violentas dos pais em relação às filhas diante de uma situação concreta de gravidez. Esse comportamento dos pais gera mais sofrimen- 
to e apreensão nas adolescentes, que admitiram as inúmeras conseqüências e mudanças que iriam acontecer em suas vidas com o advento da maternidade.

Analisando o discurso das adolescentes, pode-se também perceber que o comportamento diferenciado dos pais em relação à criação das filhas e filhos interfere diretamente na formação da identidade dos mesmos e na postura que eles assumem em relação a sexualidade. As meninas e meninos, como as próprias adolescentes se intitulam, pensam e agem de forma bem distinta.

Os meninos se interessam mais precocemente pela iniciação sexual (12, 13,14 anos), são mais desinibidos e não se preocupam com as consequências, como as doenças sexualmente transmissíveis e gravidez. Priorizam o prazer e não se preocupam com as fofocas que possam gerar seu comportamento. Muitas vezes são estimulados pelos pais e grupos de amigos a terem relações sexuais como uma prova de masculinidade.

As meninas são mais controladas pela família, iniciam mais tarde a vida sexual e apresentam muitos temores em relação à gravidez e a doenças sexualmente transmissíveis, assim como receiam os comentários gerados e a responsabilização pela relação sexual.

Vários estudos analisam o comportamento diferenciado de adolescentes do sexo feminino e masculino em situações relacionadas à sexualidade, como a iniciação sexual, gravidez, aborto e maternidade e apresentam um ponto comum, que é a maior atribuição de responsabilidades às mulheres, com distintas repercussões na adolescência e vida adulta ${ }^{(16-19)}$.

Outro aspecto evidenciado no discurso das adolescentes que reforça essas diferenças refere-se aos sentimentos e expectativas envolvidos na iniciação sexual. Para as adolescentes, as manifestações de amor e carinho são requisitos indispensáveis na decisão de iniciar um relacionamento sexual, além da reciprocidade: um deve gostar do outro. As expectativas em relação ao namorado são bastante amplas: ser verdadeiro, sensível, amoroso, carinhoso, educado, honesto, gentil, fiel, ter respeito pela namorada, dentre outras.

Os sentimentos e as expectativas femininas, centrados no desejo e no prazer, contrastam com a descrição do comportamento dos adolescentes do sexo masculino, com quem elas convivem. Apesar desta disparidade entre o imaginário e a realidade, elas sonham em encontrar um namorado que preencha e atenda a todas suas expectativas.

Uma outra situação referente a relacionamentos afetivos - intitulada o ficar - surgiu nos relatos das adolescentes. Para elas essa situação representa relacionamentos eventu- ais, com troca de carícias, sem vínculos pessoais ou mesmo um compromisso duradouro e que traz algumas vantagens sobre o namoro, como a possibilidade de conhecer mais pessoas e de haver menos cobranças nas relações. $\mathrm{O}$ ficar pode ou não se transformar em namoro, dependendo dos adolescentes sentirem-se seguros para um compromisso e vínculo amoroso. As adolescentes reconheceram, de forma unânime, o direito feminino de propor o início de um relacionamento afetivo, porém apenas algumas relataram sentirem-se à vontade para tomar iniciativas numa conquista amorosa.

Essa fase de experimentação afetiva entre os adolescentes apresenta uma distinção do ficar masculino e feminino. Para os meninos é permitido ficar com várias meninas, sendo esse comportamento é aceito e incentivado pelo grupo, reforçando, muitas vezes, o poder da virilidade masculina. Para as meninas, tal situação assume uma conotação distinta e desvantajosa. Ficar com diferentes meninos pode gerar discriminações e até mesmo rótulos que desabonariam a imagem da adolescente. Mesmo diante dessas diferenças, a autora reconhece que esse tipo de relacionamento afetivo tem trazido mudanças no comportamento dos adolescentes em diferentes segmentos sociais, favorecendo a vivência de relações amorosas ${ }^{(8)}$.

Em relação aos medos mais freqüentes apresentados pelas adolescentes referentes à iniciação sexual formaram-se dois grupos, considerando os medos comuns e os específicos por idades.

Como medos comuns destacam-se a possibilidade de gravidez, a sensação de dor na primeira relação, o medo da reação dos pais e dos comentários gerados na comunidade onde vivem (fofocas), de adquirir doenças sexualmente transmissíveis, como também o medo de o namorado não ter ereção no momento da relação sexual. Todos os grupos demonstram ter conhecimento sobre os medicamentos e práticas alternativas usados para a impotência sexual. Mencionaram o ovo de codorna, amendoim e destacaram o uso do Viagra como uma solução simples e imediata para esse tipo de problema. Quando questionadas sobre como adquiriram informações sobre esse medicamento, elas apontaram as novelas, filmes, revistas e conversas com amigas.

Em relação às doenças sexualmente transmissíveis a AIDS foi destacada pelas adolescentes, sendo mencionados, além do medo de contágio com o HIV, os sentimentos de culpa, raiva, vergonha, rejeição e negação gerados pela doença. As adolescentes demonstraram estar cientes quanto à importância e formas de prevenção da AIDS. Diferentes estudos reforçam questões semelhantes ao discutirem doenças sexualmente transmissíveis com jovens ${ }^{(20-21)}$. 
Dentre os medos apresentados em todos os grupos pelas adolescentes, a possibilidade de gravidez foi considerada $o$ pior deles, sendo essa posição reforçada em diferentes momentos da Oficina. O medo da gravidez mostra-se diretamente relacionado a situações vividas no ambiente doméstico, como a advertência frequiente da família quanto às conseqüências de uma gravidez, o comportamento violento e repressor dos pais, assim como a convivência com mães adolescentes que tiveram de redirecionar suas vidas e de assumir a criação do filho.

Como medos específicos para as adolescentes com mais idade, destacaram-se os medos de decepcionar o parceiro, da camisinha estourar no momento da relação e o de ser desprezada pelo namorado.Esses medos também refletem situações concretas vividas pelas adolescentes, como a instabilidade nos relacionamentos afetivos e a necessidade de agradar ao parceiro.

Para as adolescentes que estão iniciando suas experiências afetivo-sexuais, as emoções borbulham e os conflitos mostram-se muito freqüentes e intensos, gerando muita ansiedade para solução imediata dos mesmos.

As adolescentes mais novas mencionaram principalmente o medo de serem expulsas de casa pelos pais, caso ficassem grávidas. Durante as discussões sobre essa situação, distintas histórias foram contadas, reforçando reações violentas dos pais no momento da notícia da gravidez, o ato da expulsão de casa, o retorno, após um determinado tempo, com aceitação pelos pais. Em todos os relatos ficou evidente o sofrimento vivenciado pela adolescente e sua família. As agressões físicas e verbais, assim como outros tipos de violência, foram citados pelas adolescentes, sem nenhum tipo de questionamento, mostrando, de forma subentendida e natural, a violência como parte do seu cotidiano.

A análise global dos discursos evidenciou aspectos interligados e ao mesmo tempo contraditórios na concepção do feminino e masculino, apontando as relações de poder presentes no processo da iniciação sexual das adolescentes.

A compreensão das relações de poder é fundamental na discussão acerca da sexualidade, considerando

a multiplicidade de correlações de forças imanentes ao domínio, o jogo que, através de lutas e afrontamentos incessantes as transforma, reforça, inverte; os apoios que tais correlações de forças encontram umas nas outras, formando cadeias ou sistemas ou, ao contrário, as defasagens e contradições que as isolam entre si, enfim, as estratégias em que se originam e cujo esboço geral ou cristalização institucional toma corpo nos aparelhos estatais, na formulação da lei, nas hegemonias sociais(22).

Partindo dessa concepção, o autor discute o poder como um exercício produtivo das relações sociais e questiona a existência de um poder único, hegemônico, externalizado como repressor, associado muitas vezes a classes sociais, relações de gênero e ao Estado.

Inúmeras situações relatadas pelas adolescentes retrataram as relações de poder no cotidiano vivido, apresentando poucas reações ou resistência a elas. A reflexão sobre essa realidade vivida pelas adolescentes, considerando seu contexto social e cultural, reforçou a importância de levar em conta as relações de gênero para compreender a construção singular do pensamento feminino e masculino, entender as pressões sociais sofridas por esta geração, os princípios e sentimentos que norteiam suas atitudes e comportamentos. Permitiu, ainda, perceber que as questões de gênero apresentam estreito vínculo com diferentes atividades da vida cotidiana e interferem nas relações sociais. Ao analisar as relações de gênero foi possível ir além do significado atribuído ao masculino e feminino e compreender as consequiências de viver como homens e mulheres dentro de práticas sociais concretas.

O entendimento das questões de gênero contribuiu ainda para a identificação das representações sociais das adolescentes acerca da iniciação sexual.

\section{Processo de elaboração das representações sociais das adolescentes acerca da iniciação sexual}

Na medida em que buscamos identificar e compreender a dimensão cognitiva, afetiva e as práticas cotidianas contidas nos discursos das adolescentes sobre a iniciação sexual, aproximamos-nos das suas representações. O conhecimento já construído acerca dos sujeitos, de suas famílias, dos valores referentes à sexualidade apresentados por elas e pela sociedade, da influência das relações de gênero na identidade do adolescente, formam uma teia de informações da qual emergem duas representações acerca da iniciação social:

- Deixar de ser criança

- Temor pela gravidez e suas conseqüências

Para compreendê-las foi necessário retornar às três dimensões (cognitiva, afetiva e prática cotidiana), buscando a influência das mesmas no processo de elaboração das representações. Devido ao modo em que foram colhidos os dados na modalidade de Oficina e das características singulares desse grupo, consideramos importante destacar alguns aspectos referentes às três dimensões acima mencionadas.

Na dimensão cognitiva, em que se busca o conhecimento assimilado e circulante no grupo, foi possível observar um nível de conhecimento diferenciado do mesmo sobre as modificações que ocorrem no corpo do adolescente, sobre as questões ligadas à fecundação, gravidez, prevenção de DST, aos métodos contraceptivos, e outros. Vale ressaltar que esses conhecimentos foram construídos de forma gra- 
dual, pelo próprio grupo, no decorrer de várias Oficinas de Sexualidade, das quais elas participaram.

Os aspectos afetivos também interferiram na construção das representações das adolescentes, dentre eles a descoberta de emoções, o desejo de conhecer algo novo, os relacionamentos amorosos. No imaginário das adolescentes, essas descobertas foram acompanhadas, muitas vezes, de mitos e tabus relacionados à sexualidade e à iniciação sexual, o que gerou ansiedade e apreensão. A possibilidade de uma gravidez acarreta muitos medos, diante da responsabilidade que é atribuída às mulheres na maternidade e das mudanças inevitáveis na vida da adolescente.

$\mathrm{Na}$ prática cotidiana as adolescentes vivenciaram situações concretas de colegas que tiveram a vida redirecionada em função de uma gravidez precoce. No convívio familiar a figura materna assume a responsabilidade pela criação dos filhos e, muitas vezes, pelo sustento do lar. A figura masculina, quando presente, tem comportamentos que refletem o poder, a dominação e pouco envolvimento com a criação dos filhos. As reações violentas vivenciadas pelas adolescentes no meio familiar reforçaram o sentimento de medo diante de uma gravidez e até mesmo diante da iniciação sexual.

Analisando essas dimensões, pode-se perceber a relação estreita entre cognição, afeto e ação contidas nas representações das adolescentes acerca da iniciação sexual, as quais são construídas nas relações sociais estabelecidas na família e no grupo próximo a elas.

Ao conhecer tais representações, está-se identificando, conjuntamente, as diferentes posições assumidas pelas adolescentes em relação à iniciação sexual, os saberes comuns ao grupo social a que pertencem e, ainda, como esses saberes foram construídos.

\section{CONCLUSÃO}

Para a adolescente, a iniciação sexual mostra-se como um momento importante de escolha e de definições na vivência da sexualidade, desencadeando sentimentos diferenciados, que se agrupam em dois blocos: o desejo e o medo. Tais sentimentos não são estáticos, algumas vezes se distanciam e outras se aproximam.

\section{REFERÊNCIAS}

(1) Martínez TP, Pascual CP. Compreender a sexualidade: para uma orientação integral. São Paulo: Paulinas; 1998. (Coleção: Adolescência e Juventude).

(2) Melo AV, Yazaki LM. O despertar do desejo. In: Secretaria de Estado da Economia e Planejamento de São Paulo, Fundação SEAD. Vinte anos no ano 2000: estudos sócio-demográficos sobre a juventude paulista. São Paulo; 1998. p. 119-25.
Assim, o DESEJO está relacionado à possibilidade de descobrir novas emoções, deixar de ser criança, ser amada e respeitada, ser reconhecida, ser independente e ser feliz. $\mathrm{O}$ MEDO, por outro lado, refere-se à possibilidade de uma gravidez precoce e de suas consequiências, tais como: reação violenta dos pais, o desprezo dos familiares e do namorado, os comentários no meio em que vive a respeito da sua iniciação sexual, as cobranças feitas e as responsabilidades geradas pela maternidade e, ainda, o resultado de assumir sozinha a criação dos filhos e de alterar seus planos futuros.

O entendimento desses sentimentos requer uma análise mais ampla, voltada para as relações de gênero e suas interferências na vivência sexual e na subjetividade da adolescente, considerando a freqüência com que eles emergiram no seu discurso.

Em relação à iniciação sexual, alguns aspectos merecem ser destacados, tais como: mitos e tabus interferindo nas decisões das adolescentes; comportamento diferenciado dos pais em relação às filhas e aos filhos; controle da sociedade sobre a sexualidade da mulher; responsabilidades unilaterais a serem assumidas pela mulher e mudanças nos planos futuros, caso ocorra uma gravidez.

Entendemos que as questões de gênero mostram-se imprescindíveis à compreensão dos processos de construção dos sujeitos sociais, da lógica que direciona a organização dos papéis propostos para o sexo feminino e masculino, e das interferências das relações de gênero nas decisões das adolescentes acerca da sexualidade. A discussão dessas questões assume um caráter emancipatório na medida em que questiona a lógica interna da construção da diferença, propõe uma postura mais crítica diante dos papéis sociais atribuídos a homens e mulheres e motiva as adolescentes a se tornarem agentes de mudança no meio em que vivem, reconhecendo o lugar social da mulher e reivindicando seus direitos. Entendemos que, quando discutimos as questões de gênero, já começamos a transformá-las.

Acreditamos que o entendimento das representações sociais das adolescentes acerca da iniciação sexual e sua interface entre a identidade feminina será de grande importância para a avaliação e redirecionamento dos trabalhos desenvolvidos com as adolescentes, subsidiando debates e reflexões sobre a vivência de uma sexualidade saudável e responsável pelos jovens.

(3) Weller S. Salud reproductiva de los/as adolescentes, Argentina, 1990-1998. In: Oliveira MC, organizadora. Cultura, adolescência, saúde. Campinas: Consórcio de Programas em Saúde Reprodutiva e Sexualidade na América Latina/CEDE/ COLMEX/NEPO/UNICAMP; 2000. p. 9-43. 
(4) Stern C, Medina G. Adolescência y salud en México. In: Oliveira MC, organizadora. Cultura, adolescência, saúde. Campinas: Consórcio de Programas em Saúde Reprodutiva e Sexualidade na América Latina/CEDE/COLMEX/NEPO/UNICAMP; 2000. p. $98-160$.

(5) Lescano EL. Adolescência e anticoncepção: estudos de adolescentes atendidas na maternidade do Hospital de Apoio de Sullana (HAS), Peru [dissertação]. São Paulo: Faculdade de Saúde Pública da USP; 2002.

(6) Hughes J, McCauley AP. Improving the fit: adolescents' needs and future programs for sexual and reproductive health in developing countries. Stud Fam Plann. 1998;29(2):233-45.

(7) Calazans G. Cultura adolescente e saúde: perspectivas para investigação. In: Oliveira MC, organizadora, Cultura, adolescência, saúde. Campinas: Consórcio de Programas em Saúde reprodutiva e sexualidade na América latina/CEDE/COLMEX/ NEPO/UNICAMP; 2000. p. 44-97.

(8) Domingues C. Identidade e sexualidade no discurso adolescente [dissertação]. São Paulo: Faculdade de Saúde Pública da USP; 1997.

(9) Goldemberg M. A arte de pesquisar: como fazer pesquisa qualitativa em ciências sociais. $4^{\mathrm{a}}$ ed. Rio de Janeiro: Record; 2000.

(10) Minayo MC. O desafio do conhecimento: pesquisa qualitativa em saúde. $8^{\text {a }}$ ed. São Paulo: Hucitec; 2004.

(11) Moscovici S. A representação social da psicanálise. Trad. de Álvaro Cabral. Rio de Janeiro: Zahar; 1978.

(12) Nóbrega SM. Sobre a teoria das representações sociais. In: Moreira ASP, organizador. Representações sociais: teoria e prática. João Pessoa: Ed. Universitária; 2001. p. 55-87.
(13) Jordelet D. As representações sociais. Rio de Janeiro: Ed. UERJ; 2001. Representações sociais: um domínio em expansão; p. 17-44.

(14) Alves-Mazzotti AJ. O planejamento de pesquisas qualitativas. In: Alves-Mazzotti AJ, Gewandsznajder F. O método nas ciências naturais e sociais: pesquisa quantitativa e qualitativa . $2^{\mathrm{a}}$ ed. São Paulo: Pioneira; 2001. p. 147-76.

(15) Shinyashiki R. Pais + filhos, companheiros de viagem. $6^{\mathrm{a}}$ ed. São Paulo: Gente; 1992.

(16) Costa M. Sexualidade na adolescência: dilemas do crescimento. $5^{\mathrm{a}}$ ed. Porto Alegre: L\&PM; 2002.

(17) Desser AD. Adolescência, sexualidade \& culpa. Rio de Janeiro: Rosa dos Tempos; 1993.

(18) Guimarães BEM, Coli AS. Gravidez na adolescência. Goiânia: Ed. UFG; 1998.

(19) Martins DA. A sexualidade sob o ponto de vista de adolescentes do sexo feminino [dissertação]. Ribeirão Preto: Escola de Enfermagem de Ribeirão Preto/USP; 2002.

(20) Thiengo MA, Oliveira DC, Rodrigues BMRD. Representações sociais do HIV/AIDS entre adolescentes: implicações para os cuidados de enfermagem. Rev Esc Enferm USP. 2005;39(1):68-76.

(21) Barros MNS. Saúde sexual e reprodutiva. In: Contini MLJ, Koller SH, Santos MN. Adolescência e psicologia: concepções, práticas e reflexões críticas. Rio de janeiro: Conselho Federal de Psicologia; 2002. p. 46-54.

(22) Foucault M. História da sexualidade I: a vontade de saber. $14^{\mathrm{a}}$ ed. Rio de Janeiro: Graal; 2001. 